Original Article

\title{
MALONDIALDEHYDE, ADIPONECTIN, NITRIC OXIDE, C-REACTIVE PROTEIN, TUMOR NECROSIS FACTOR-ALPHA AND INSULIN RESISTANCE RELATIONSHIPS AND INTER- RELATIONSHIPS IN TYPE 2 DIABETES EARLY STAGE. IS METFORMIN ALONE ADEQUATE IN THIS STAGE?
}

\author{
ENTSAR A. SAAD ${ }^{1}{ }^{*}$, SALEM A. HABIB ${ }^{1,2}$, WAEL A. REFAI ${ }^{3}$, AMIRA A. ELFAYOUMY ${ }^{1}$
}

${ }^{1}$ Chemistry Department, Faculty of Science, Damietta University, Damietta, Egypt, ${ }^{2}$ Department of Biochemistry, Faculty of Science, University of Tabuk, Saudi Arabia, ${ }^{3}$ Internal Medicine Department, Medical Research Institute, Alexandria University, Alexandria, Egypt Email: entsarsaad@gmail.com

Received: 05 Jul 2017 Revised and Accepted: 31 Aug 2017

\begin{abstract}
Objective: Great interest is directed to inflammation and oxidative stress involvement in type 2 diabetes pathogenesis. Many researchers suggest they play roles but exactly how is still not clear enough. This encouraged us to investigate relations and potential inter-relationships between them and insulin resistance in type 2 diabetes in its early stage. Whether metformin drug alone, as frequently prescribed, is enough for type 2 diabetes management in this early stage was also an objective.
\end{abstract}

Methods: Blood sugar indices, adiponectin (ADIPOQ), tumor necrosis factor- $\alpha$ (TNF- $\alpha$ ), malondialdehyde (MDA), nitric oxide (NO), C-reactive protein (CRP), liver and kidney function tests and lipid profile were monitored in non-diabetic volunteers, pre-diabetic and newly diagnosed type 2 diabetic patients before and after metformin drug utilization for 5 mo.

Results: MDA, inflammation markers and alanine aminotransferase (ALT) were elevated, and blood sugar indices and lipid profile showed pathological alterations in diabetics compared to non-diabetics; changes were worse in type 2 cases. They were improved to different degrees by metformin treatment except for pancreatic $\beta$-cells function and ADIPOQ level showed no significant improvements and it couldn't normalize ALT.

Conclusion: Results reflected significant relations and inter-relationships between oxidative stress and inflammation markers in type 2 diabetes in its early stage and indicated that metformin may need to be combined with another drug.

Keywords: Free radicals, Lipid peroxidation, Oxidative stress, Inflammation, Pre-diabetes, Metformin

(C) 2017 The Authors. Published by Innovare Academic Sciences Pvt Ltd. This is an open access article under the CC BY license (http://creativecommons.org/licenses/by/4.0/) DOI: http://dx.doi.org/10.22159/ijpps.2017v9i10.21149

\section{INTRODUCTION}

Diabetes mellitus is a heterogeneous metabolic disease with high incidence; it affects over 300 million of global population and it represents the second most common cause of death after cancer [1$3]$. Type 2 diabetes is the most common among diabetes mellitus known types. The latter is manifested by insulin resistance, $\beta$-cells dysfunction, chronic inflammation and enhanced glucose output by the liver [4]. Frequently, its treatment begins with lifestyle management and/or prescribing of metformin [5].

Lengthy pre-diabetic (also named impaired glucose tolerance or impaired fasting glucose) duration usually persists prior to the development of type 2 diabetes. Characteristic features of the prediabetic stage are insulin resistance and fasting blood sugar (FBS) level more than normal but still lower than that in type 2 diabetes, there are no obvious manifestations of pre-diabetes; some cases may have some type 2 diabetes symptoms. Individuals with pre-diabetes are advised to be tested for type 2 diabetes every two years [6, 7].

Until now insulin resistance is known to be the main cause of type 2 diabetes development due to insulin hormone wide range of effects. Recently, many researchers have been interested in studying other contributors in type 2 diabetes pathogenesis; particularly inflammation, oxidative stress and immune conditions. Most of them suggest they play roles but exactly how they are inter-related is still not clear enough.

Acute inflammation is initiated by cells already present in all tissues, mainly resident macrophages and kupffer cells. Cytokines produced by macrophages and other cells of the innate immune system to mediate the inflammatory response and some immune conditions that changes their expression pattern has been suggested to cause type 2 diabetes $[8,9]$. Tumor necrosis factor alpha (TNF- $\alpha$ ) is a proinflammatory cytokine secreted chiefly by macrophages. It is responsible for stimulation of local inflammation in adipocytes and induction of acute phase reaction $[8,10]$. Insulin resistance showed alterations in TNF- $\alpha$ metabolism indicating that those alterations may influence type 2 diabetes onset [11]. Adiponectin (ADIPOQ) is the only adipocytokine that acts as an anti-inflammatory; it has the ability to inhibit synthesis of major pro-inflammatory cytokines such as TNF- $\alpha$ [8]. ADIPOQ level is usually inversely associated with BMI in health and disease [12]. It represents about $0.01 \%$ of all plasma proteins and it is declined in diabetics compared to non-diabetics [13]. It was also found to have anti-diabetic and insulin-sensitizing properties [14]. C-reactive protein (CRP) is an acute-phase protein produced by the liver. It is a sensitive systemic biomarker of inflammation. It correlates with development of insulin resistance and it has been considered as one of the main contributing agents for type 2 diabetes development [8]. NO was postulated by Manisundar et al. [15] as an inflammatory biomarker. It is an inflammatory mediator; its synthesis and release can be stimulated by macrophages and other inflammatory cells. Its level may give information about severity and state of underlying disease process. More production of NO was observed in diabetes [16].

Free radicals are very reactive and harmful species that produced normally under normal metabolic conditions if excessively produced or not adequately scavenged via anti-oxidation defence system, oxidative stress state results [17]. Free radicals can damage all components of the cell especially lipids [18]. In 1994, Kalavacherla et al. [19] stated that malondialdehyde (MDA) evaluation seems to be a sensitive marker of inflammation in patients with rheumatoid arthritis. In fact, lipid peroxidation is involved in the pathogenesis of numerous diseases including hepato-cellular [20,21], renal [22] and 
cardiovascular diseases [23], diabetes [3], obesity [23] and cancer [24-26].

This study was aimed primarily to assess the relations and interrelations between inflammation, oxidative stress, insulin resistance and type 2 diabetes in its early stage and secondly to evaluate metformin performance in this early stage as the first line drug for type 2 diabetes treatment.

\section{MATERIALS AND METHODS}

\section{Kits}

ADIPOQ, TNF- $\alpha$, MDA and NO kits were purchased from SigmaAldrich 3050 Spruce Street, Saint Louis, MO 63103 USA. Kit for insulin was obtained from Roche Diagnostics, Risch-Rotkreuz, Switzerland. Other kits for the rest of the studied biochemical parameters were obtained from Siemens Healthcare Diagnostics Inc. Newark, DE19714 USA.

\section{Subjects}

This study was conducted on 80 adult non-obese participants, with body mass index $(\mathrm{BMI})<30$, who were selected by Dr. Wael A. Refai Internal Medicine Department, Medical Research Institute,
Alexandria University, Alexandria, Egypt) (table 1). They were recruited from the visitors of the outpatient department in the internal medicine clinics after a physical examination, laboratory reports of blood tests, diagnosis, and application of inclusion and exclusion criteria according to world health organization (WHO) guidelines. Medical history of all participants was recorded. They were divided into three groups. Group I (non-diabetic group); 30 normal healthy adults do not suffer from diabetes and any other interfering disease. Group II (pre-diabetic group); 20 patients diagnosed as pre-diabetics with FBS and glycated hemoglobin (HbA1C) within the ranges of 5.6-7.0 $\mathrm{mmol} / \mathrm{l}$ and $5.7-6.4 \%$, respectively. Group III (newly diagnosed diabetic group); 30 newly diagnosed diabetes mellitus type 2 patients with no history of diabetes medications, FBS from $7.5 \mathrm{mmol} / \mathrm{l}$ and above with $\mathrm{HbA1C}$ from $6.5 \%$ and above, one blood sample was collected once the patient is diagnosed as diabetes mellitus type 2 (before starting any treatment), then after five months of starting metformin treatment (500 mg twice daily) one another blood sample was collected for follow-up. The current clinical observational study was carried out in accordance with the Declaration of Helsinki of World Medical Association and it was approved by Faculty of Science, Damietta University, Egypt. Written informed consents from all participants were obtained.

Table 1: General characteristics of study subjects

\begin{tabular}{llll}
\hline Groups & $\begin{array}{l}\text { Non-diabetic group } \\
(\mathbf{n = 3 0 )}\end{array}$ & $\begin{array}{l}\text { Pre-diabetic group } \\
(\mathbf{n = 2 0})\end{array}$ & $\begin{array}{l}\text { Diabetic group (newly diagnosed) } \\
\text { (n=30) }\end{array}$ \\
\hline Age (y) & $31-38$ & $34-42$ & $43-53$ \\
Male & 6 & 5 & 5 \\
Female & 24 & 15 & 25 \\
BMI & $<30$ & $<30$ & $<30$ \\
FBS (mmol/l) & $<5.5$ & $5.6-7.0$ & $\geq 7.5$ \\
HbA1C & $<5.5$ & $5.7-6.4$ & $\geq 6.5$ \\
Duration of diabetes type 2 & - & - & - \\
disease & - & Lifestyle & First month: Lifestyle (diet and exercise) \\
Management plan & & (diet and exercise) & Starting from the second month: metformin (glucophage) with \\
& - & - & dosage of 500 mg twice daily \\
Accompanying diseases & - & - & - \\
Accompanying medications & - & & \\
\hline
\end{tabular}

$\mathrm{n}=80$. BMI; body mass index, FBS; fasting blood sugar and HbA1C; glycated hemoglobin.

\section{Samples}

Venous blood samples were obtained from participants via vein puncture after 10-12 h of fasting. Sera were separated by centrifugation at $5000 \mathrm{rpm}$ for $10 \mathrm{~min}$ and were used for estimation of different biochemical parameters.

\section{Biochemical measurements}

The following parameters were estimated according to their kits instructions: adipokines [ADIPOQ and TNF- $\alpha$ ], inflammation markers [CRP and NO], liver function tests [total protein (TP), albumin (ALB), total bilirubin (T-BILI) and ALT], lipid profile [total cholesterol (CHOL), high-density lipoprotein (HDL), low-density lipoprotein (LDL) and triglycerides (TG)], kidney function tests [creatinine, blood urea nitrogen (BUN) and uric acid], FBS, HbA1C and fasting insulin.

Insulin resistance was estimated by the homeostatic model assessment (HOMA IR) [HOMA IR $=\{$ Fasting insulin $(\mu \mathrm{IU} / \mathrm{ml}) x$ Fasting glucose $(\mathrm{mmol} / \mathrm{l}) / 22.5\}]$. Pancreatic $\beta$-cells function was estimated by HOMA-derived $\beta$-cells function (HOMA \%B) [HOMA \%B=20 x Fasting insulin $(\mu \mathrm{IU} / \mathrm{ml}) /$ Fasting glucose ( $\mathrm{mmol} / \mathrm{l})-3.5]$. Insulin sensitivity was estimated by HOMA-derived insulin sensitivity (HOMA \%S) [HOMA $\% \mathrm{~S}=$ Fasting glucose $(\mathrm{mmol} / \mathrm{l}) /$ Fasting insulin $(\mu \mathrm{IU} / \mathrm{ml})]$. Insulin resistance was defined as HOMA IR $>2$ [23].

\section{Statistical analysis}

The obtained results are expressed as means and standard deviations (mean \pm SD). Analysis was done using SPSS version 16 software and unpaired t-test was used to compare variables between each two groups. Correlations were performed between the studied parameters using Spearman correlation. For all analyses $\mathrm{p}<0.05$ was considered significant.

\section{RESULTS}

FBS, HbA1C, insulin and HOMA IR mean levels were significantly $(p<0.001)$ increased while HOMA \%S mean level was significantly $(p<0.001)$ decreased in all diabetic cases including pre-diabetics and newly diagnosed diabetics (before and after treatment) compared to non-diabetic control cases. Similar behaviour was observed when diabetic cases (before treatment) were compared with the pre-diabetic cases. All these levels were declined $(p<0.001)$ by metformin treatment except insulin sensitivity that was significantly increased. However, HOMA \%B was increased $(p<0.05)$ in pre-diabetic cases while it was decreased $(p<0.001)$ in the newly diagnosed diabetic cases either before or after metformin treatment compared to non-diabetic cases. It is worthy to state that there was no significant improvement observed in pancreatic $\beta$-cells function in diabetic cases after treatment with metformin (table 2). 
Table 2: Diabetic profile of the studied groups

\begin{tabular}{|c|c|c|c|c|}
\hline \multirow[t]{2}{*}{ Groups } & \multirow{2}{*}{$\begin{array}{l}\text { Non-diabetic group } \\
(n=30)\end{array}$} & \multirow{2}{*}{$\begin{array}{l}\text { Pre-diabetic group } \\
(n=20)\end{array}$} & \multicolumn{2}{|c|}{ Diabetic group (newly diagnosed) $(n=30)$} \\
\hline & & & Before treatment & After metformin treatment for 5 mo \\
\hline FBS (mmol/l) & $5.0 \pm 0.37$ & $6.14 \pm 0.41^{\mathrm{c}}[+22.8 \%]$ & $9.07 \pm 1.53^{\mathrm{c}, \mathrm{III}}[+81.4 \%]$ & $7.8 \pm 1.33^{\mathrm{c}, \mathrm{III}, * * *}\{-14.0 \%\}$ \\
\hline Insulin (pmol/l) & $59.92 \pm 8.42$ & $123.22 \pm 13.85^{\mathrm{c}}[+105.6 \%]$ & $147.51 \pm 14.91^{\mathrm{c}, \text { III }}[+146.2 \%]$ & $108.07 \pm 9.92^{\mathrm{c}, \mathrm{III}, * * *}\{-26.7 \%\}$ \\
\hline $\operatorname{HbA1C}(\%)$ & $4.94 \pm 0.36$ & $6.02 \pm 0.32^{\mathrm{c}}[+21.9 \%]$ & $8.41 \pm 1.13^{\mathrm{c}, \mathrm{III}}[+70.2 \%]$ & $7.22 \pm 0.68^{\mathrm{c}, \mathrm{III}, * * *}\{-14.1 \%\}$ \\
\hline HOMA IR & $1.12 \pm 0.16$ & $2.37 \pm 0.24 c[+111.6 \%]$ & $3.07 \pm 0.32^{\mathrm{c}, \mathrm{III}}[+174.1 \%]$ & $2.20 \pm 0.24{ }^{\mathrm{C}, \mathrm{I}, * * *}\{-28.3 \%\}$ \\
\hline НОМА \%В & $103.73 \pm 15.67$ & $114.57 \pm 19.84^{\mathrm{a}}[+10.5 \%]$ & $67.24 \pm 18.09$ c,III $[-35.2 \%]$ & $69.60 \pm 17.77$ c,III $\{+3.5 \%\}$ \\
\hline HOMA \%S & $91.81 \pm 17.68$ & $42.55 \pm 4.35^{c}[-53.7 \%]$ & $32.92 \pm 3.51^{\mathrm{c}, \mathrm{III}}[-64.1 \%]$ & $45.88 \pm 4.96^{\mathrm{cII}, * * *}\{+39.4 \%\}$ \\
\hline
\end{tabular}

Data are expressed as means and standard deviations (mean \pm SD). $n=80$. a, b and c are significantly different from the non-diabetic group at $\mathrm{p}<0.05$, $\mathrm{p}<0.01$ and $\mathrm{p}<0.001$, respectively. I, II and III are significantly different from the pre-diabetic group at $\mathrm{p}<0.05, \mathrm{p}<0.01$ and $\mathrm{p}<0.001$, respectively. $*, * *$ and $* * *$ are significantly different from the diabetic group before treatment at $\mathrm{p}<0.05, \mathrm{p}<0.01$ and $\mathrm{p}<0.001$, respectively. Value in $]$ represents $\%$ increase $(+)$ or decrease (-) from non-diabetic. Value in $\{$ represents \% increase (+) or decrease (-) from diabetic before treatment. FBS; fasting blood sugar, HbA1C; glycated hemoglobin, HOMA IR; insulin resistance, HOMA\%B; HOMA-derived $\beta$-cell function, and HOMA\%S; HOMA-derived insulin sensitivity.

As shown in table 3 , contents of serum MDA, NO, CRP, TNF- $\alpha$ $(\mathrm{p}<0.001)$ and ADIPOQ $(\mathrm{p}<0.01)$ were significantly elevated in the prediabetic and newly diagnosed diabetic group before treatment compared to the non-diabetic group. Levels of NO, CRP and TNF- $\alpha$ were significantly $(\mathrm{p}<0.001)$ higher and ADIPOQ was non-significantly
( $p>0.05$ ) higher but MDA was significantly $(p<0.001)$ lower in sera of diabetic cases before treatment compared to pre-diabetic ones. Treatment of diabetic subjects with metformin lowered all these levels significantly $(\mathrm{p}<0.001)$ except for ADIPOQ which was non-significantly lowered compared to their levels before treatment.

Table 3: Lipid peroxidation (MDA), nitric oxide (NO), and systemic inflammation markers levels in the studied groups

\begin{tabular}{|c|c|c|c|c|}
\hline \multirow[t]{2}{*}{ Groups } & \multirow{2}{*}{$\begin{array}{l}\text { Non-diabetic group } \\
(n=30)\end{array}$} & \multirow[t]{2}{*}{ Pre-diabetic group $(n=20)$} & \multicolumn{2}{|c|}{ Diabetic group (newly diagnosed) $(n=30)$} \\
\hline & & & Before treatment & After metformin treatment for $5 \mathrm{mo}$ \\
\hline \multirow[t]{2}{*}{$\mathrm{CRP}(\mathrm{mg} / \mathrm{l})$} & \multirow[t]{2}{*}{$1.87 \pm 0.41$} & $7.11 \pm 1.31^{\mathrm{c}}$ & $11.34 \pm 1.79 \mathrm{c}, \mathrm{III}$ & $3.56 \pm 0.43^{\mathrm{c}, I I I, * * *}$ \\
\hline & & {$[+280.2 \%]$} & {$[+506.4 \%]$} & $\{-68.6 \%\}$ \\
\hline \multirow[t]{2}{*}{ MDA (nmol/l) } & \multirow[t]{2}{*}{$3.01 \pm 0.21$} & $11.02 \pm 0.44^{\mathrm{c}}$ & $8.99 \pm 0.72^{\mathrm{c}, \mathrm{III}}$ & $4.22 \pm 0.5^{\mathrm{c}, \mathrm{III}, * * *}$ \\
\hline & & {$[+266.1 \%]$} & [+198.7\%] & $\{-53.1 \%\}$ \\
\hline \multirow[t]{2}{*}{ NO (nmol/l) } & \multirow[t]{2}{*}{$25.17 \pm 0.73$} & $40.18 \pm 1.45^{\mathrm{c}}$ & $58.13 \pm 3.56^{\mathrm{c}, \text { III }}$ & $31.24 \pm 2.5^{\mathrm{c}, \mathrm{III}, * * *}$ \\
\hline & & {$[+59.6 \%]$} & {$[+130.9 \%]$} & $\{-46.3 \%\}$ \\
\hline \multirow[t]{2}{*}{ TNF- $\alpha(\mathrm{pg} / \mathrm{ml})$} & \multirow[t]{2}{*}{$75.83 \pm 9.28$} & $98.38 \pm 5.95^{c}$ & $150.9 \pm 28.6^{\mathrm{c}, \mathrm{III}}$ & $61.72 \pm 3^{\mathrm{c}, \mathrm{III},{ }^{* * *}}$ \\
\hline & & {$[+29.7 \%]$} & {$[+99.0 \%]$} & $\{-59.1 \%\}$ \\
\hline ADIPOQ (pg/ml) & $31850 \pm 2450.0$ & $\begin{array}{l}33519 \pm 784.14^{b} \\
{[+5.2 \%]}\end{array}$ & $\begin{array}{l}33633 \pm 1223.14^{b} \\
{[+5.6 \%]}\end{array}$ & $\begin{array}{l}33084 \pm 1460.5^{a} \\
\{-1.6 \%\}\end{array}$ \\
\hline
\end{tabular}

Data are expressed as means and standard deviations (mean \pm SD). $n=80$. a, b and c are significantly different from the non-diabetic group at $\mathrm{p}<0.05$, $\mathrm{p}<0.01$ and $\mathrm{p}<0.001$, respectively. I, II and III are significantly different from the pre-diabetic group at $\mathrm{p}<0.05, \mathrm{p}<0.01$ and $\mathrm{p}<0.001$, respectively. ${ }^{*}, * *$ and ${ }^{* * *}$ are significantly different from the diabetic group before treatment at $\mathrm{p}<0.05, \mathrm{p}<0.01$ and p $<0.001$, respectively. Value in [ ] represents $\%$ increase $(+)$ or decrease (-) from non-diabetic. Value in \{\} represents \% increase $(+)$ or decrease (-) from diabetic before treatment. CRP; C-reactive protein, ADIPOQ; adiponectin and TNF- $\alpha$; tumor necrosis factor alpha.

As illustrated in table 4, both BUN and uric acid concentrations were significantly elevated $(\mathrm{p}<0.05-\mathrm{p}<0.001)$ while creatinine levels were not affected in all the studied groups compared to control nondiabetic group. Significant elevations $(p<0.05-p<0.001)$ in TG, LDL and CHOL with a significant decline $(\mathrm{p}<0.01-\mathrm{p}<0.001)$ in HDL levels in all the studied groups compared to the non-diabetic group were also recorded. After metformin treatment, CHOL and LDL levels were significantly lowered $(\mathrm{p}<0.001)$.
Table 4 also reflects that ALT activity was significantly $(\mathrm{p}<0.001)$ increased in pre-diabetics and diabetics compared to nondiabetics and metformin treatment could not normalize ALT level while it kept total protein, albumin and total bilirubin within their normal ranges.

Table 5 showed significant correlations found between sugar profile, lipid peroxidation and inflammation markers.

Table 4: Renal and lipid profiles in addition to liver function tests of the studied groups

\begin{tabular}{|c|c|c|c|c|}
\hline \multirow[t]{2}{*}{ Groups } & \multirow{2}{*}{$\begin{array}{l}\text { Non-diabetic group } \\
(n=30)\end{array}$} & \multirow[t]{2}{*}{ Pre-diabetic group $(n=20)$} & \multicolumn{2}{|c|}{ Diabetic group (newly diagnosed) $(n=30)$} \\
\hline & & & Before treatment & After metformin treatment for 5 mo \\
\hline Creatinine $(\mu \mathrm{mol} / \mathrm{l})$ & $62.33 \pm 10.2$ & $66.20 \pm 12.32$ & $60.89 \pm 9.07$ & $62.93 \pm 8.91$ \\
\hline BUN (mmol/l) & $3.1 \pm 1.0$ & $4.15 \pm 0.83^{c}$ & $4.25 \pm 0.62^{\mathrm{c}}$ & $4.43 \pm 0.30^{c}$ \\
\hline Uric acid $(\mu \mathrm{mol} / \mathrm{l})$ & $248.7 \pm 39.24$ & $278.25 \pm 55.45^{\mathrm{a}}$ & $285.77 \pm 29.94^{c}$ & $290.83 \pm 21.99 c$ \\
\hline CHOL (mmol/l) & $4.07 \pm 0.86$ & $4.69 \pm 0.9^{a}$ & $5.01 \pm 0.28^{c}$ & $4.22 \pm 0.65^{\mathrm{I}, * * *}$ \\
\hline $\mathrm{TG}(\mathrm{mmol} / \mathrm{l})$ & $0.83 \pm 0.36$ & $1.49 \pm 0.68^{c}$ & $1.68 \pm 0.13^{c}$ & $1.75 \pm 0.24^{c}$ \\
\hline $\mathrm{HDL}(\mathrm{mmol} / \mathrm{l})$ & $1.32 \pm 0.27$ & $1.09 \pm 0.28^{b}$ & $1.00 \pm 0.19 \mathrm{c}$ & $1.01 \pm 0.14 \mathrm{c}$ \\
\hline $\mathrm{LDL}(\mathrm{mmol} / \mathrm{l})$ & $2.45 \pm 0.77$ & $3.06 \pm 0.87^{a}$ & $3.67 \pm 0.30^{\mathrm{c}, \mathrm{II}}$ & $2.86 \pm 0.66^{\mathrm{a}, * * *}$ \\
\hline $\mathrm{TP}(\mathrm{g} / \mathrm{l})$ & $78.03 \pm 4.23$ & $78.85 \pm 3.7$ & $80.33 \pm 3.01^{\mathrm{a}}$ & $79.70 \pm 2.84$ \\
\hline $\operatorname{ALB}(\mathrm{g} / \mathrm{l})$ & $38.93 \pm 4.13$ & $38.1 \pm 4.19$ & $38.60 \pm 2.99$ & $40.00 \pm 2.51^{*}$ \\
\hline T-BILI $(\mu \mathrm{mol} / \mathrm{l})$ & $8.53 \pm 2.32$ & $7.15 \pm 2.64^{b}$ & $7.21 \pm 0.40^{\mathrm{b}}$ & $8.35 \pm 0.55^{1, * * *}$ \\
\hline $\operatorname{ALT}(\mathrm{U} / \mathrm{l})$ & $35.7 \pm 6.04$ & $42.85 \pm 10.84^{c}$ & $42.93 \pm 5.75^{\mathrm{c}}$ & $42.13 \pm 4.23^{c}$ \\
\hline
\end{tabular}

Data are expressed as means and standard deviations (mean \pm SD). $n=80$. a, b and c are significantly different from the non-diabetic group at $\mathrm{p}<0.05$, $\mathrm{p}<0.01$ and $\mathrm{p}<0.001$, respectively. I, II and III are significantly different from the pre-diabetic group at $\mathrm{p}<0.05, \mathrm{p}<0.01$ and $\mathrm{p}<0.001$, respectively. $*, * *$ and ${ }^{* * *}$ are significantly different from the diabetic group before treatment at $\mathrm{p}<0.05, \mathrm{p}<0.01$ and $\mathrm{p}<0.001$, respectively. BUN; blood urea nitrogen, 
CHOL; total cholesterol, TG; triglycerides, HDL; high-density lipoprotein, LDL; low-density lipoprotein, TP; total protein, ALB; albumin, T-BILI; total bilirubin and ALT; alanine aminotransferase.

Table 5: Correlations between sugar profile parameters, malondialdehyde (MDA), nitric oxide (NO), and systemic inflammation markers

\begin{tabular}{|c|c|c|}
\hline Correlation between & $\mathbf{r}$ & p value \\
\hline FBS and CRP & 0.345 & $<0.001$ \\
\hline FBS and ADIPOQ & 0.343 & $<0.001$ \\
\hline FBS and TNF- $\alpha$ & 0.744 & $<0.001$ \\
\hline FBS and MDA & 0.682 & $<0.001$ \\
\hline FBS and NO & 0.842 & $<0.001$ \\
\hline $\mathrm{HbA} 1 \mathrm{C}$ and $\mathrm{CRP}$ & 0.499 & $<0.001$ \\
\hline HbA1C and ADIPOQ & 0.311 & 0.001 \\
\hline $\mathrm{HbA} 1 \mathrm{C}$ and TNF- $\alpha$ & 0.631 & $<0.001$ \\
\hline HbA1C and MDA & 0.645 & $<0.001$ \\
\hline HbA1C and NO & 0.804 & $<0.001$ \\
\hline Insulin and CRP & 0.848 & $<0.001$ \\
\hline Insulin and ADIPOQ & 0.399 & $<0.001$ \\
\hline Insulin and TNF- $\alpha$ & 0.251 & $<0.01$ \\
\hline Insulin and MDA & 0.586 & $<0.001$ \\
\hline Insulin and NO & 0.548 & $<0.001$ \\
\hline HOMA IR and CRP & 0.821 & $<0.001$ \\
\hline HOMA IR and ADIPOQ & 0.417 & $<0.001$ \\
\hline HOMA IR and TNF- $\alpha$ & 0.366 & $<0.001$ \\
\hline HOMA IR and MDA & 0.639 & $<0.001$ \\
\hline HOMA IR and NO & 0.649 & $<0.001$ \\
\hline HOMA $\%$ B and TNF- $\alpha$ & -0.758 & $<0.001$ \\
\hline HOMA \%B and MDA & -0.539 & $<0.001$ \\
\hline HOMA \%B and NO & -0.790 & $<0.001$ \\
\hline HOMA \%S and CRP & -0.692 & $<0.001$ \\
\hline HOMA $\%$ S and ADIPOQ & -0.469 & $<0.001$ \\
\hline HOMA $\%$ S and TNF- $\alpha$ & -0.468 & $<0.001$ \\
\hline HOMA \%S and MDA & -0.764 & $<0.001$ \\
\hline HOMA \%S and NO & -0.705 & $<0.001$ \\
\hline CRP and NO & 0.316 & 0.001 \\
\hline ADIPOQ and NO & 0.365 & $<0.001$ \\
\hline TNF- $\alpha$ and NO & 0.919 & $<0.001$ \\
\hline ADIPOQ and TNF- $\alpha$ & 0.279 & $<0.01$ \\
\hline CRP and MDA & 0.297 & $<0.01$ \\
\hline ADIPOQ and MDA & 0.414 & $<0.001$ \\
\hline TNF- $\alpha$ and MDA & 0.789 & $<0.001$ \\
\hline NO and MDA & 0.871 & $<0.001$ \\
\hline CRP and ADIPOQ & 0.274 & $<0.01$ \\
\hline
\end{tabular}

n=80. FBS; fasting blood sugar, HbA1C; glycated hemoglobin, HOMA-IR; insulin resistance, HOMA\%B; HOMA-derived $\beta$-cell function, and HOMA\%S; HOMA-derived insulin sensitivity, CRP; C-reactive protein, ADIPOQ; adiponectin and TNF- $\alpha$; tumor necrosis factor alpha.

\section{DISCUSSION}

In pre-diabetics as obviously illustrated in table 2, about $23 \%$ increment in FBS level was accompanied by high insulin resistance (112\% higher than normal). As an adaptive response pancreatic $\beta$ cells function was subsequently augmented by about $11 \%$. As a result, insulin production was increased by about $106 \%$ than normal. Even though, sensitivity to insulin was significantly lowered by about $54 \%$ compared to non-diabetic control indicating frustration of blood glucose adjustment. If not controlled, high blood glucose level continued to be higher, ultimately resulting in type 2 diabetes. These results are supportive for insulin resistance as the main risk factor for type 2 diabetes as previously reported by [8]. FBS increase allows more glycation of body proteins as evidenced by the observed increment in glycated hemoglobin by about $22 \%$. Protein glycation interferes with cellular functioning and induces reactive oxygen species production as side products such as $\mathrm{H}_{2} \mathrm{O}_{2}$. The latter, if not scavenged, can ultimately damage various body cells including pancreatic $\beta$-cells which are at high risk. This led us to assume that high FBS stimulates lipid peroxidation.

In the present investigation and in agreement with [27] and [16] both pre-diabetics and diabetics showed higher serum MDA than non-diabetic controls by $266.1 \%$ and $198.7 \%$, respectively. These levels showed great significant $(\mathrm{p}<0.001)$ positive associations with FBS, HOMA IR, HbA1C and insulin and negative ones with HOMA \%S and HOMA \%B. These observations support the assumption that impaired glucose control can directly elevate lipid peroxidation may via more glycation of body proteins as discussed above or via insulinopenia-induced release of free radicals from hexose monophosphate shunt and fatty acids $\beta$-oxidation metabolic pathways or via hyperglycemia-induced platelets aggregation that leads to production of thromboxane, prostaglandins and other molecules which are a common source of free radicals or via antioxidant defense system impairment. Furthermore, MDA might link protein glycation with further lipid peroxidation. This could be explained by MDA role in stabilization of collagen via MDA crosslinking that encourages more excessive glycation which start further lipid peroxidation. Moreover, as previously reported by [28] high MDA can induce many inflammatory cytokines. These cytokines trigger others production and lead to more oxidative stress [29]. Upon the aforementioned, in a way or another diabetes induces lipid peroxidation, lipid peroxidation stimulates inflammation and inflammation, in turn, stimulates more lipid peroxidation supporting the involvement of oxidative stress in chronic inflammation. This is proved by the significant $(\mathrm{p}<0.01-\mathrm{p}<0.001)$ positive correlations found in the current study between MDA levels and the levels of inflammation markers; CRP, TNF- $\alpha$ and NO. Upon all we can confirm MDA as an additional sensitive marker for inflammation, and support oxidative stress inclusion in type 2 diabetes pathogenesis as an important contributor.

Type 2 diabetes was previously assumed as an immune-dependent disease by Sepehri et al. [9]. Present study results indicate chronic 
production of oxidative stress and inflammation biomarkers in type 2 diabetes as CRP, NO, TNF- $\alpha$ and MDA were produced in higher levels in pre-diabetic cases than in non-diabetics and continued to be more-higher in the newly diagnosed cases with type 2 diabetes. Besides they were positively correlated with FBS, HbA1C, insulin, HOMA IR and negatively correlated with HOMA \%S indicating their contribution in type 2 diabetes pathogenesis. Thus, one can consider diabetes as an inflammatory disease, thereby it is immunedependent.

Comparing to pre-diabetes, once type 2 diabetes begins to develop as represented by our newly diagnosed diabetic group $\beta$-cells function became abnormal; it showed a decrease by 35\% than normal. FBS became progressively worse and its level continued its elevation up to $81 \%$ over normal thereby glycated hemoglobin was increased to $70 \%$. Insulin hormone level was increased to $146 \%$ but body became more less-sensitive to insulin (HOMA \%S was decreased by $64 \%$ than normal) indicating further insulin resistance existence evidenced by HOMA IR increase to $174 \%$ higher than normal. These results support that more insulin resistance actually causes type 2 diabetes.

Because CRP, MDA, NO and TNF- $\alpha$ were significantly $(\mathrm{p}<0.001)$ elevated by about $280 \%, 266 \%, 60 \%$ and $30 \%$, respectively in prediabetic cases compared to non-diabetics and CRP, NO and TNF- $\alpha$ became higher to about 506\%, 131\% and 99\%, respectively in patients with diabetes type 2 while MDA became lower (about $199 \%$ ) but still significantly extremely higher than non-diabetics. In addition, all of them were significantly $(\mathrm{p}<0.01-\mathrm{p}<0.001)$ positively correlated with each other. So they could be used as early predictors for both pre-diabetes and diabetes type 2 and it is worthy to state that our results reveal their priority, regarding their $\%$ of the increase, in the following order: $\mathrm{CRP}>\mathrm{MDA}>\mathrm{NO}>\mathrm{TNF}-\alpha$. Even though ADIPOQ was also positively correlated, ADIPOQ lower significancy ( $\mathrm{p}<0.01$ vs. $\mathrm{p}<0.001$ for others) and lower percent of increase (about $5.2,5.6 \%$ vs. about $280,506 \% ; 266,199 \% ; 60,131 \%$ and $30,99 \%$ for CRP, MDA, NO and TNF- $\alpha$ in pre-diabetics and diabetics, respectively) led us to revoke its role as an early predictor. Further evidence for CRP superiority in this issue is its significant positive correlation with insulin resistance $(r=0.373$ and $\mathrm{p}<0.05$, data not shown) in newly diagnosed cases with type 2 diabetes. This finding was in harmony with [8] and [30].

It is well known that disturbances in glucose homeostasis induce platelets aggregation and adhesion. So, NO elevation in the current study may be explained on the basis of its ability to act as an inhibitor of this aggregation and adhesion. Accordingly, NO elevation was reasonable mainly to void hyperglycemia-induced platelets aggregation. A positive correlation $(\mathrm{r}=0.428$ and $\mathrm{p}<0.05$, data not shown) found between NO and MDA in newly diagnosed diabetic group confirm complex interaction that occurs between NO and other produced free radicals in diabetes. Thus, disturbances in NO production and metabolism could be also assumed as one of the causes of diabetes development. Besides, NO elevation reveals more severe inflammation as it was positively correlated with CRP in this group ( $\mathrm{r}=0.893$ and $\mathrm{p}<0.001$, data not shown). Both elevated and decreased levels of NO end products were observed previously in patients with diabetes in different investigations [16].

On contrary to Swaroop et al. [31], our TNF- $\alpha$ positive correlations with FBS, HbA1C, HOMA IR $(\mathrm{p}<0.001)$ and insulin $(\mathrm{p}<0.01)$ and negative correlations with HOMA \%B and HOMA \%S (p<0.001) may reveal that TNF- $\alpha$ can induce insulin resistance and suppress the subsequent $\beta$-cells compensatory over-functioning. It was believed that TNF- $\alpha$ plays an important role in the inhibition of insulin transduction, also it had an effect on glucose metabolism [32, 33]. However; Bluher et al. [34] stated that TNF- $\alpha$ have no role in early stage insulin resistance pathogenesis.

Little increase in levels of ADIPOQ in diabetic studied cases here was also expected to cope with the elevated pro-inflammatory cytokine TNF- $\alpha$ and others produced by adipocytes in a trial to ameliorate their deleterious effects in diabetic patients. This was evidenced via positive correlation found between ADIPOQ and TNF- $\alpha(p<0.01)$. This with ADIPOQ great positive associations with FBS, HbA1C, insulin and HOMA IR and negative association with HOMA \%S confirm body's fat ability to cause continuous (chronic) levels of internal inflammation that changes insulin's action and contributes to diabetes disease. On contrary, it was previously found that ADIPOQ level is positively associated with insulin sensitivity and negatively with TNF- $\alpha[8]$.

In the present work, ALT was significantly higher $(\mathrm{p}<0.001)$ in prediabetics and diabetics than in non-diabetics. This indicates hepatocellular damage beginnings as reported before by Toson et al. [35]. BUN and uric acid levels were also increased $(p<0.05-p<0.001)$, whereas levels of creatinine were not affected by pre-diabetes or diabetes development in its early stage indicating that renal complications may appear later in diabetes if not well controlled. But hyper-lipidemia was evidenced in pre-diabetes or type 2 diabetes in its early stage via observed significant elevations ( $p<0.05-p<0.001)$ in TG, LDL and CHOL with significant lowering in HDL level $(p<0.01-p<0.001)$ indicating the risk for future cardiovascular complications. Moreover, the significant association found with FBS ( $r=0.267$ and $\mathrm{p}<0.01$, data not shown), TG $(\mathrm{r}=0.222$ and $p<0.05$, data not shown) and uric acid confirm the implication of uric acid in the risk factors for type 2 diabetes and cardiovascular complications. This was in agreement with Bailey et al. [36].

As usual our newly diagnosed patients with type 2 diabetes were directed to lifestyle management for one month then they were instructed to use metformin with a dosage of $500 \mathrm{mg}$ twice daily. Treatment with metformin alone for duration of 5 mo resulted in significant $(\mathrm{p}<0.001)$ but not adequate improvements (ranged from $14 \%$ to $39.4 \%$ ) in diabetic profile parameters and in inflammation markers as well (ranged from $46.3 \%$ to $68.6 \%$ ) however; function of $\beta$-cells showed too little (3.5\%) non-significant improvement and anti-inflammatory cytokine ADIPOQ showed non-significant decrease by $1.6 \%$ in relation to its level before treatment. The most affected parameter in the diabetic profile was insulin sensitivity; that was increased by $39.4 \%$ after treatment. This was expected because it is well-known that metformin acts to improve insulin sensitivity [36]. Metformin exerts its action firstly on the liver to reduce glucose production and, secondly, on the peripheral tissues mainly muscles to augment glucose uptake [37]. In the present work and in accordance with [37], to higher extent than that showed in diabetic profile metformin was able to significantly improve endothelial dysfunction (evidenced by $46.3 \%$ decrease in NO content), decline oxidative stress (evidenced by $53.1 \%$ decrease in MDA concentration), and to reduce inflammation (evidenced by $68.6 \%$ decline in CRP level and by $59.1 \%$ decline in TNF- $\alpha$ ). Additionally, metformin treatment for 5 mo had no significant effect on levels of creatinine, BUN, uric acid, TG and HDL but it was able to decrease cholesterol and LDL levels $(p<0.001)$ reflecting its ability to decline risk factors for cardiovascular complications. Furthermore, metformin treatment for 5 mo could not normalize ALT level although it was able to keep TP, ALB and T-BILI within their normal levels. These results together confirm that, in our studied cases, metformin management of type 2 diabetes does not display sufficient control, especially glycemic control thus it may need to add-on therapy.

\section{CONCLUSION}

In the current study, significant relations and inter-relationships between oxidative stress, inflammation and insulin resistance in type 2 diabetes in its early stage were proved. Simply, our results reveal the existence of a violent cycle; lipid peroxidation stimulates inflammation and inflammation stimulates more lipid peroxidation, more inflammation causes more insulin resistance, more insulin resistance causes type 2 diabetes, type 2 diabetes induces more lipid peroxidation and the cycle returned again.

Thereby, type 2 diabetes can be considered as an inflammatory disease, thus it is immune-dependent. When metformin alone was used for 5 mo to manage type 2 diabetes in this early stage it did not show sufficient success thus it may need to be combined with another drug that favorably operates via an insulinindependent pathway to get better performance. These aspects contribute to a more comprehensive and more detailed perspective of type 2 diabetes etiology, pathogenesis and future treatment strategies. 


\section{AUTHOR CONTRIBUTION}

This work was done by all authors cooperatively.

\section{LIMITATION}

Number of pre-diabetic or newly diagnosed diabetic patients within the time of the study was low so to some extent our sample size was small. Other studies on larger sample size are recommended for more confirmation.

\section{CONFLICT OF INTERESTS}

The authors declare that there is no conflict of interest regarding the publication of this article.

\section{REFERENCES}

1. Sreenivas RA, Meera S, William E, Kumar JS. Correlation between glycemic control and lipid profile in type 2 diabetic patients: HbA1c as an indicator of dyslipidemia. Asian J Pharm Clin Res 2014;7:153-5.

2. Dhaliwall C, Erinmacpherson, Richardson J. Effectiveness of telephone-delivered interventions for increasing physical activity levels in persons with type 2 diabetes or hypertension: a systematic review. J Crit Rev 2015;2:6-11.

3. Saad EA, Hassanien MM, El-Hagrasy MA, Radwan KH. Antidiabetic, hypolipidemic and antioxidant activities and protective effects of Punica granatum peels powder against pancreatic and hepatic tissues injuries in streptozotocin induced IDDM in rats. Int J Pharm Pharm Sci 2015;7:397-402.

4. Jain R, Jain P, Jain P. A review on treatment and prevention of diabetes mellitus. Int J Curr Pharm 2016;8:16-8.

5. Nathan DM, Buse JB, Davidson MB, Ferrannini E, Holman RR, Sherwin R, et al. Medical management of hyperglycemia in type 2 diabetes: a consensus algorithm for the initiation and adjustment of therapy: a consensus statement of the American diabetes association and the European association for the study of diabetes. Diabetes Care 2009;32:193-203.

6. Liberty IA, Kodim N. Assess prediabetes risk, as a golden period for prevention of diabetes. Asian J Pharm Clin Res 2017;10:349-53.

7. Melmed S. Type 2 diabetes mellitus. In: Williams Textbook of Endocrinology. 13 ${ }^{\text {th }}$ ed. Philadelphia, Pa.: Elsevier; 2016.

8. Rehman K, Akash MSH. Mechanisms of inflammatory responses and development of insulin resistance: how are they interlinked? Rehman Akash J Biomed Sci 2016;23:87.

9. Sepehri Z, Kiani Z, Nasiri AA, Kohan F. Toll-like receptor 2 and type 2 diabetes. Cell Mol Biol Lett 2016;21:2.

10. Gustafson B. Adipose tissue, inflammation and atherosclerosis. J Atheroscler Thromb 2010;17:332-41.

11. Al-Dahr MSH, Jiffri EH. Increased adipose tissue expression of tumor necrosis factor-alpha and insulin resistance in obese subjects with type II diabetes. World J Med Sci 2010;5:30-5.

12. Koch A, Sanson E, Voigt S, Helm A, Trautwein C, Tacke F. Serum adiponectin upon admission to the intensive care unit may predict mortality in critically ill patients. Crit Care 2011;26:166-74.

13. Coppola A, Marfella R, Coppola L, Tagliamonte E, Fontana D, Liguori E, et al. Effect of weight loss on coronary circulation and adiponectin levels in obese women. Int J Cardiol 2009;134:414-6.

14. Ouchi N, Walsh K. Adiponectin as an anti-inflammatory factor. Clin Chim Acta 2007;380:24-30.

15. Manisundar N, Julius A, Amudhan A, Hemalatha VT, Manigandan T. Nitric oxide as an inflammatory biomarker in oral and systemic diseases-a systematic review. Middle-East J Sci Res 2014;20:881-6.

16. Bhatia S, Shukla R, Madhu SV, Gambhir JK, Prabhu KM. Antioxidant status, lipid peroxidation and nitric oxide end products in patients of type 2 diabetes mellitus with nephropathy. Clin Biochem 2003;36:557-62.

17. Saad EA. Curative and protective effects of L-arginine on carbon tetrachloride induced hepatotoxicity in mice. Biochem Biophys Res Commun 2012;423:147-51.
18. Saad EA, Habib SA. Effect of crude extracts of some medicinal plants on the osmotic stability of human erythrocytes in vitro. J Free Radicals Antioxidants photon 2013;139:265-72.

19. Kalavacherla US, Ishaq M, Rao UR, Sachindranath A, Hepsiba T. Malondialdehyde as a sensitive marker of inflammation in patients with rheumatoid arthritis. J Assoc Physicians India 1994;42:775-6.

20. Saad EA. Non-invasive assessment of liver fibrosis using serum markers. J Pharm Chem Biol Sci 2014;2:59-76.

21. Saad EA, Toson EA, Ahmed GM. Clove or green tea administration antagonizes khat hepatotoxicity in rats. Int J Pharm Pharm Sci 2015;7:72-6.

22. Saad EA. Kidney response to L-arginine treatment of carbon tetrachloride induced hepatic injury in mice. Nat Sci 2013;5:1-6.

23. Habib SA, Saad EA, Elsharkawy AA, Attia ZR. Pro-inflammatory adipocytokines, oxidative stress, insulin, $\mathrm{Zn}$ and $\mathrm{Cu}$ : Interrelations with obesity in Egyptian non-diabetic obese children and adolescents. Adv Med Sci 2015;60:981-71.

24. Saad EA, Hassanien MM, Elneely EA. Iron(III) diacetylmonoxime-2-hydrazinopyridine complex: a new prospective antitumor drug. Appl Organometal Chem 2017;31:e3684. Doi:10.1002/aoc.3684.

25. Saad EA, Hassanien MM, El-Lban FW. Nickel(II) diacetyl monoxime-2-pyridyl hydrazone complex can inhibit Ehrlich solid tumor growth in mice: a potential new antitumor drug. Biochem Biophys Res Commun 2017;484:579-85.

26. Saad EA, Hassanien MM, El-Mezayen H, ELmenawy NM. Regression of murine ehrlich ascites carcinoma using synthesized cobalt complex. Med Chem Commun 2017;8:1103-11.

27. Noberasco G, Odetti P, Boeri D, Maiello M, Adezati L. Malondialdehyde (MDA) level in diabetic subjects. Relationship with blood glucose and glycosylated hemoglobin. Bionred Pharmucother 1991;45:193-6.

28. David F, Farley J, Huang H, Lavoie JP, Laverty S, Farley, et al. Cytokine and chemokine gene expression of IL-1beta stimulated equine articular chondrocytes. Vet Surg 2007;36:221-7.

29. Chokkalingam V, Tel J, Wimmers F, Liu X, Semenov S, Thiele J, et al. Probing cellular heterogeneity in cytokine-secreting immune cells using droplet-based microfluidics. Lab Chip 2013;13:4740-4.

30. Pradhan AD, Manson JE, Rifai N, Buring JE, Ridker PM. Creactive protein, interleukin 6 , and risk of developing type 2 diabetes mellitus. JAMA 2001;286:327-34.

31. Swaroop JJ, Rajarajeswari D, Naidu JN. Association of TNF- $\alpha$ with insulin resistance in type 2 diabetes mellitus. Indian J Med Res 2012;135:127-30.

32. Aguirre V, Uchida T, Yenush L, Davis R, White MF. The c-Jun $\mathrm{NH} 2$-terminal kinase promotes insulin resistance during association with insulin receptor substrate-1 and phsosphorylation of Ser (307). J Biol Chem 2000;275:9047-54.

33. Zou C, Shao J. Role of adipocytokines in obesity-associated insulin resistance. J Nutr Biochem 2008;19:277-86.

34. Bluher M, Kratzsch J, Paschke R. Plasma levels of tumor necrosis factor-alpha, angiotensin II, growth harmone, and IGF1 are not elevated in insulin-resistant obese individuals with impaired glucose tolerance. Diabetes Care 2001;24:328-34.

35. Toson ESA, Habib SA, Saad EA, Harraz NH. Toxic and antifertility effects of Alocasia macrorrhiza and Calotropis procera ethanolic extracts on male mice. Int J Biochem Photon 2014; 195:328-38.

36. Gopal MN, Sridhar C. A validated stability indicating a ultraperformance liquid chromatographic method for simultaneous determination of metformin hydrochloride and empagliflozin in bulk drug and tablet dosage form. Int J Appl Pharm 2017;9:45-50.

37. Rojas LBA, Gomes MB. Metformin: an old but still the best treatment for type 2 diabetes. Diabetol Metab Syndr 2013;5:6.

\section{How to cite this article}

- $\quad$ Entsar A Saad, Salem A Habib, Wael A Refai, Amira A Elfayoumy. Malondialdehyde, adiponectin, nitric oxide, C-reactive protein, tumor necrosis factor-alpha and insulin resistance relationships and inter-relationships in type 2 diabetes early stage. Is metformin alone adequate in this stage? Int J Pharm Pharm Sci 2017;9(10):176-181. 